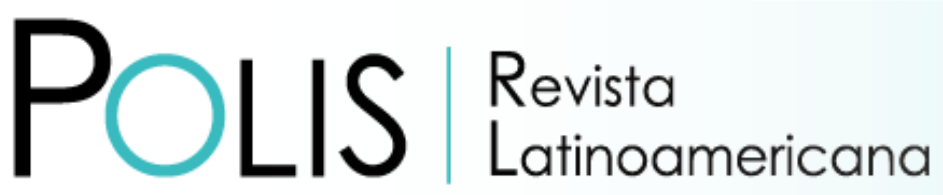

V20 | N60 | 2021

DOI: $10.32735 /$ S0718-6568/2021-N60-1659

\title{
Mujeres interventoras en pandemia: sobre la infancia y su representación
}

\author{
Iskra Pavez-Soto \\ Universidad Bernardo O'Higgins, Santiago, Chile \\ Email: iskra.pavez@ubo.cl \\ Juan Ortiz-López \\ Universidad de Las Américas, Santiago, Chile \\ Email: jortizl@udla.cl \\ Monique Ap. Voltarelli \\ Universidade de Brasília, Brasília, Brasil \\ Email: mvoltarelli@unb.br
}

Recibido: 31.05.2021 ｜Ａceptado: 11.08.2021

\begin{abstract}
Resumen: El objetivo de este artículo es indagar en las representaciones sociales de infancia de mujeres interventoras, en dos dimensiones: 1) la infancia migrante como actor que demanda intervención en pandemia; y 2) la propia experiencia de infancia de las mujeres interventoras, en tanto subjetividad. Se utilizó una metodología cualitativa, mediante cuestionario autoadministrado, en formato electrónico. Se aplicó un análisis de contenido e interseccional. La muestra estuvo constituida por veinticuatro mujeres profesionales, técnicas y voluntarias, de diversas nacionalidades que trabajan en organizaciones no gubernamentales en regiones de la zona norte y centro de Chile. Se concluye que las mujeres interventoras identifican una representación de la niñez migrante como un sujeto carente, en situación de desamparo y vulneración de derechos que afecta su calidad de vida, más aún en una época de crisis sanitaria y escasa respuesta institucional. Como contrapunto, la propia experiencia de infancia de las mujeres interventoras emerge como una representación diversa, donde se visibiliza el protagonismo de una sujeta actuante que habla en primera persona, incluso en la adversidad. Así, el análisis interseccional de la representación -o representaciones- de la infancia -o infancias- se torna en un insumo que nutre la praxis.
\end{abstract}

Palabras Clave: Mujeres, niñez, migración, intervención, pandemia.

\section{Women interveners during the pandemic: on childhood and its representation}

Abstract: The aim of this article is to investigate the social representations of childhood in
a group of women interveners in two dimensions: 1) migrant childhood, like actor that de-
mands intervention in a pandemic; and 2) the experience of childhood of the women is
analyzed, from a biographical approach. A qualitative methodology was used, through a
self-administered questionnaire, in electronic format. A content and intersectional analyses
were applied. The sample consisted of twenty-four professional, technical and volunteer
women of various nationalities who work in NGOs in regions of the northern and central zone
of Chile. It is concluded that the intervening women identify a representation of migrant 
children as a lacking subject, in a situation of helplessness and violation of rights that affect their quality of life, even more so in a time of health crisis and scarce institutional response. As a counterpoint, the childhood experience of the intervening women emerges as a diverse representation, where the protagonism of an acting subject who speaks in the first person is visible, even in adversity. Thus, the intersectional analysis of the representation -or representations- of childhood -or childhoods- becomes an input that nourishes praxis.

Keywords: Women, childhood, migration, intervention, pandemic.

\section{Mulheres interventoras na pandemia: sobre a infância e sua representação}

Resumo: O objetivo deste artigo é investigar nas representações sociais da infância de um grupo de mulheres interventoras, em duas dimensões: 1) a infância migrante, como um ator que demanda intervenção em pandemia; y 2) a vivência da infância das intervenientes, a partir de uma abordagem biográfica. Utilizou-se uma metodologia qualitativa, por meio de questionário autoaplicável, em formato eletrônico, que evidenciou o uso da chamada linguagem inclusiva e foi aplicada uma análise de conteúdo e interseccional. A amostra foi composta por vinte e quatro mulheres profissionais, técnicas e voluntárias de várias nacionalidades que trabalham em organizações não governamentais nas regiões da zona norte e centro do Chile. Conclui-se que as mulheres intervenientes identificam uma representação da criança migrante como sujeito carente, em situação de desamparo e violação de direitos que afeta a sua qualidade de vida, ainda mais num momento de crise de saúde e pouca resposta institucional. Em contraponto, a experiência de infância das intervenientes surge como uma representação diversa, onde é visível o protagonismo de um sujeito agente que fala na primeira pessoa, mesmo na adversidade. Assim, a análise interseccional da representação -ou representações- da infância -ou da infância- torna-se um insumo que alimenta a práxis.

Palavras-chave: Mulheres, infância, migração, intervenção, pandemia.

\section{Como citar este artículo:}

Pavez-Soto, I., Ortiz-López, J. y Voltarelli, M. Ap. (2021). Mujeres interventoras en pandemia: sobre la infancia y su representación. Polis Revista Latinoamericana, 20 (60), 110-129. doi: http://dx.doi.org/10.32735/S0718-6568/2021-N60-1659

\section{Introducción}

La pandemia del virus COVID 19 ha impactado la sociedad global y ha generado una crisis que nos obliga a revisar los fundamentos que sostienen la vida moderna. Vivimos en una época de incertidumbre, una época de cambios o un cambio de época. Además, en el caso de Chile, el estallido social trajo crispación y una interpelación a las instituciones públicas que arrastraban una crisis de legitimidad desde hacía tiempo y que hoy nos tiene en un proceso constituyente. La pandemia ha condensado la exclusión de grupos sociales que ya vivían en condiciones de fragilidad previamente, como la infancia migrante. Por ejemplo, en la región latinoamericana la pobreza en general ha aumentado (14.5\%) y aún más la infantil (7,6\%)(CEPAL, 2020; UNICEF, 2021). Las medidas de confinamiento obligaron a crear programas de escolarización a distancia, sin embargo, la educación remota se vio afectada por la baja calidad del servicio de internet o la falta de equipamiento 
tecnológico. Además, aumentó el desempleo y la presencia de niñez trabajadora (UNICEF, 2021; CEPAL, 2020). Por otro lado, ciertos flujos migratorios se han acelerado, por ejemplo, solo en Venezuela se estima que han salido más de cinco millones de personas, incluso ha causado conmoción la presencia de niñas, niños y adolescentes en las llamadas "caravanas de migrantes" (UNICEF, 2021). En el actual contexto pandémico y unido a la reciente promulgación de la nueva Ley de Migración en Chile, se generó el aumento de los ingresos clandestinos o por pasos no habilitados de personas venezolanas y haitianas, principalmente (Servicio Jesuita a Migrantes, SJM, 2021). En Chile, se han notificado casos infantiles de contagio del virus y fallecimientos (DEIS, 2021). Igualmente el confinamiento ha afectado las relaciones intergeneracionales al interior de las familias, mayor estrés (Cabieses, 2020) y estado de ánimo de las niñas y los niños (CIPER, 2021). Si bien se dispuso la entrega de cajas de alimentos mediante el programa de alimentación escolar (JUNAEB), el proceso fue lento (Muñoz García, 2020). Además, aumentaron las denuncias por violencia intrafamiliar y maltrato infantil. La ausencia de protocolos y programas para la acogida de migrantes y refugiados en el continente también creció con la crisis sanitaria (CEPAL-UNICEF, 2020). La falta de regularización administrativa o el desconocimiento de los derechos puede generar situaciones de mayor exclusión (Cabieses, 2020). El informe de CEPAL (2020) sobre COVID 19 y población migrante, alerta sobre la vulneración de derechos que han vivido especialmente las mujeres, las niñas y los niños y recomienda priorizar las intervenciones dirigidas a estos grupos, primando su interés superior. Es evidente que ha crecido la demanda de intervención en el período pandémico, unido a una respuesta institucional débil o sobrepasada (Alliance for Child Protection in Humanitarian Action, 2020). No obstante, en el debate público o académico, los impactos de la pandemia en la niñez han tenido poca atención.

En este escenario, el objetivo del estudio fue caracterizar las representaciones sociales de las mujeres interventoras en torno a la infancia migrante durante la pandemia y, además, se exploraron las representaciones sociales de la propia experiencia de infancia de ellas (las interventoras) desde una perspectiva interseccional, a fin de analizarlas como un contrapunto respecto a la niñez migrante de hoy. Para lograrlo, en este artículo primero se exhibe el marco teórico sobre las representaciones sociales de la infancia y la perspectiva interseccional; luego sigue la metodología para dar paso a la exposición de los resultados organizados en dos ejes temáticos: primero, los discursos sobre la infancia migrante en pandemia y segundo, la propia experiencia de las interventoras, para finalizar con algunas conclusiones.

\section{Marco teórico}

En nuestro estudio pensamos la intervención desde una perspectiva interseccional, tomando como materiales las representaciones sociales de la infancia migrante y la propia memoria de las mujeres interventoras, en diálogo con la coyuntura actual de la pandemia. Quisimos profundizar sobre las miradas de infancia, respecto al presente (alteridad, otredad) y al pasado (subjetivo, personal). Las interventoras son sujetos que no sólo controlan a través de la intervención, sino que también pueden resistir y producir cambios (Galaz, 2016, p. 5). 
El concepto de representaciones sociales de Moscovici (1988) alude a los principios y las creencias que subyacen a nuestros pensamientos e ideas hacia un objeto o asunto. Estas creencias se crean y comparten en la comunidad, ya que surgen de las interacciones sociales y del uso del lenguaje. Es decir, las representaciones sociales crean un sentido de comunidad y un sentido común de las ideas que sirven también para la validación ideológica. Por lo tanto, identificar las representaciones sociales es útil para entender las ideologías que hay detrás de las lenguas y las ideas que comparten los hablantes de una lengua (Núñez, 2021, p. 21).

Las representaciones sociales de la infancia que maneja el mundo adulto fluctúan entre imágenes dicotómicas. La infancia es vista como un paraíso perdido, altamente idealizado y cargado de felicidad e inocencia (Gaitán, 2006). Por otro lado, la niñez representa por excelencia el futuro, debido al desarrollo evolutivo, se fija la atención en el momento adulto, cuando se dejará la niñez; entonces, paradójicamente, la infancia es una especie de moratoria o confinamiento afuera del mundo adulto (Gaitán, 2006). Por último, la infancia es vista como algo irracional, porque alude al ser humano en estado salvaje, incivilizado, manipulador y aprovechador (Gaitán, 2006). Las representaciones sociales de la infancia presumen el deber ser de las niñas y los niños (Mayall, 1996). Por eso, la infancia representa un campo de saber y poder en disputa entre discursos e instituciones (científicas, políticas, religiosas o pedagógicas) (Williams, 1997).

La interseccionalidad la comprendemos como un marco analítico de la complejidad en el mundo, en las personas, y en las experiencias humanas, ya que observa a las categorías de "raza", clase, sexo-género, sexualidad, nación, habilidad, etnicidad,yedad-entreotras-como elementos interrelacionados que se moldean mutuamente (Collins y Bilge, 2020)'. Además, las elecciones y prácticas metodológicas son conductos para la teorización interseccional (Collins, 2019), lo que implica que el carácter interseccional de las categorizaciones sociales requiere deunaconstantereflexividad departe delasylosinvestigadores, parapoder desarrollar así nueva teoría. Misra, Curington y Green (2021) indican que mucha de la investigación interseccional comparte un paradigma metodológico común. Sin embargo, coinciden con Choo y Ferree (2010) en que, a pesar del impacto sustancial de la interseccionalidad en los estudios feministas, el enfoque ha sido "bajo utilizado" por las ciencias sociales (p.130).

En la aplicación analítica del marco, utilizamos los principios teóricos de la interseccionalidad propuestos por Misra, Curington y Green (2021), quienes reformularon los principios propuestos por Collins y Bilge (2020). Estas últimas autoras argumentan que la interseccionalidad se centra en seis ideas clave:

- Opresión. Cada persona se ajusta a una "matriz de dominación" que organiza jerárquicamente las relaciones de poder. Esto incluye las políticas y prácticas estructurales, la vigilancia y jerarquías burocráticas, las ideologías hegemónicas y las prácticas interpersonales y discriminatorias de las experiencias vividas cotidianamente (Collins, 2000).

\footnotetext{
1 Traducido por las autoras.
} 
- Relacionalidad. El privilegio de un grupo está directamente relacionado con la desventaja de otro (Misra et al, 2021). Por ejemplo, el ocio de mujeres blancas estadounidenses a costa del trabajo de mujeres de color.

- Complejidad. Las categorizaciones sociales de la diferencia se constituyen mutuamente y no como sistemas separados de inequidad (Collins, 1998 citada en Misra et al, 2021).

- Contexto. Existen contextos específicos en los cuales aparecen el privilegio y la desventaja (Collins \& Bilge, 2020), es crucial distinguir que estas dimensiones no representan una experiencia única de desigualdad (Misra et al, 2021).

- Comparación. La comparación es una estrategia que permite observar las diferencias en el uso del poder (Misra et al, 2021). La iteración facilita reconocer las relaciones sobresalientes que pueden ofrecer respuestas sobre la pregunta de investigación.

- Deconstrucción. Se recomienda poner atención a la maleabilidad, parcialidad y fluidez de las categorías, a fin de iterar y reconstruir o explicar el funcionamiento de la inequidad, las categorías no son dimensiones estáticas (Misra et al, 2021).

La perspectiva interseccional se abordará desde la subjetividad de las interventoras, como un ejercicio de práctico de vigilancia epistemológica (Bourdieu, 2008), considerando que tradicionalmente el sujeto profesional se sitúa desde un saber experto que genera efectos de control y disciplina en un sujeto intervenido, el cual se visualiza como una otredad en falta o carente (Galaz y Rubilar, 2019). Según Beatriz Toro (2019), el hecho de interpretar los hilos discursivos de las mujeres interventoras en el área de infancia permite visibilizar los procesos de subjetivación y las posiciones de privilegio o poder que permiten movilizar recursos simbólicos y materiales en beneficio de una alteridad situada como subalterna. Las disciplinas de la intervención social utilizan habitualmente la narración como un recurso en el ejercicio profesional (Galaz y Rubilar, 2019). En nuestro estudio se ha intentado realizar una práctica reflexiva y autocrítica, mediante el análisis de las representaciones de la infancia migrante y de la propia experiencia de infancia, como contrapuntos e insumos para la propia intervención social.

\section{Metodología}

Esta investigación surgió en el marco de un convenio del equipo de investigación y una ONG que realizaba atención con familias migrantes, quienes se plantearon la opción de crear un programa focalizado en la niñez migrante, considerando la agudización de su vulnerabilidad en la época de la pandemia. El estudio fue de carácter cualitativo, mediante cuestionario autoadministrado de forma remota y observaba dos categorías de análisis, mediante preguntas abiertas: a) la representación social de la infancia migrante en la pandemia (¿Q Qué es lo primero que siente o piensa al leer: infancia + migración + pandemia?) y b) la propia experiencia personal de infancia (¿ Cómo fue su infancia?). El contacto con las interventoras fue a través del equipo directivo de la ONG, quienes enviaron los cuestionarios en formato procesador de texto y una vez completados, se subieron a una carpeta electrónica a la cual tuvo acceso el equipo de investigación. Después de la tabulación de 
los datos, se hizo un taller de devolución con el equipo de interventoras donde se mostraron resultados preliminares y se realizó una reinterpretación colectiva de los principales hallazgos. Por lo tanto, en este artículo se da cuenta de un proceso continuo de recolección de datos, análisis y discusión con las sujetas participantes del estudio. La muestra fue de carácter opinática, estratégica o por conveniencia (Valles, 2003) atendiendo a los objetivos del estudio y según los siguientes criterios de inclusión:

- Mujeres interventoras

- Edad entre veinte y sesenta años

- Nivel de formación técnica o universitaria

- Proveniente de distintos países

- Trabajo en territorios de frontera y/o ciudades

En total, participaron veinticuatro sujetas, con una edad promedio de 39 años; entre estudiantes en práctica, profesionales, técnicas y voluntarias, oriundas de Chile, Colombia, México, Haití y España, que trabajan en regiones de la zona norte y centro del país, pertenecientes a una organización no gubernamental (ONG) que atiende a la comunidad migrante, mediante orientación jurídica e incidencia de derechos humanos, pero hasta ahora no había realizado procesos de intervención focalizada en la niñez migrante. Se estableció una autorización por escrito para participar en el estudio, con la garantía de respetar el principio de confidencialidad y anonimato. Los datos se tabularon con codificación abierta a través del análisis de contenido (latente y manifiesto), pues este método nos permitiría realizar inferencias replicables y válidas desde los textos hacia los contextos (Krippendorff, 2018).

\section{Resultados}

En primer lugar, se muestran los discursos que configuran la situación actual de la infancia migrante en la época de la pandemia. En este conjunto de relatos se aprecia que el sujeto infancia es visto como una alteridad $u$ otredad, se vincula con una imagen vulnerable $o$ vulnerabilizada, a raíz del contexto de crisis. En segundo lugar, se expone la narrativa de la propia experiencia de infancia de las mujeres interventoras, lo que conecta con su memoria y su pasado y se enarbola como subjetividad protagónica de una sujeta niña que participó activamente. Se propuso una aproximación biográfica (Pujadas, 2000) en el sentido de narrar la propia experiencia de infancia a la luz de mirar a la infancia migrante como un contrapunto, en un momento de coyuntura como lo es la pandemia. ${ }^{2}$

2 En el trabajo de campo surgió una categoría emergente referida al lenguaje inclusivo y se trata del uso de la arroba, la $\mathrm{E}$ o la $\mathrm{X}$ en reemplazo de alguna vocal en las respuestas de los cuestionarios electrónicos. La utilización de este tipo de lenguaje podría ser interpretado como una forma en que las mujeres reescriben su propia historia o herstory (Scott, 2003), en tanto historia de las mujeres (local y plural) a contrapelo de la History o Historia (en mayúscula) del Hombre (singular) o como una práctica de resistencia interseccional en el discurso. 


\section{La representación de la infancia migrante en pandemia}

La aproximación biográfica facilitó la emergencia de las expresiones subjetivas, cargadas de emociones e incluso sentimientos que podrían considerarse poco intelectuales, pero ofrecen conocer las imágenes espontáneas que surgían como primera reacción, es decir, la representación. El hecho de escribir la respuesta daba la oportunidad de hacer una simbolización y encarnarla. Aunque, esta desazón tenía un correlato empírico debido a las graves consecuencias de la crisis sanitaria. Por ejemplo, UNICEF (2021) advirtió sobre el surgimiento de niñez trabajadora en la región latinoamericana como unos de los efectos de la pandemia, en las respuestas de las interventoras se evalúa como una estrategia de subsistencia frente a un contexto extremo y se observa una afectación emocional e intelectual. La imagen de niñas y niños migrantes parados en un semáforo refleja el momento actual de crisis e incertidumbre que afecta a este grupo social en la pandemia:

"Se me viene a la cabeza a los (sic) niñas y niños que veo en las calles con sus padres, parados en los semáforos vendiendo algún producto para la sobrevivencia. Siento tristeza, me siento en deuda y que el confinamiento no les da más opción por estar los establecimientos habilitados para ell@s cerrados, como sociedad los exponemos. ¡Es triste!" (32 años, Chile, zona norte).

El sentimiento de compasión es el primero que aparece, como una representación de la niñez indefensa e inocente delante de una estructura social. Desde el marco analítico interseccional propuesto por Misra, Curington \& Green (2021), uno de los nodos de análisis que podemos observar más claramente desde un punto de vista relacional es la distribución inequitativa del privilegio. La interventora reconoce que la situación actual propone mayores desafíos a la complejidad de las categorizaciones sociales. En concreto, el actual contexto de pandemia contribuye a profundizar las condiciones de vulnerabilidad ante el ejercicio del derecho que, en este caso, empobrece el habitar de las y los migrantes. Además, creemos necesario evidenciar que dichas condiciones son establecidas estructuralmente por la legislación migratoria y sus procedimientos para el aseguramiento de su cumplimiento. Es decir, la opresión que genera el cuerpo legislativo en clave nacional repercute en las condiciones de vida y el acceso al trabajo, al cuidado y la educación en el caso de la niñez, entre otros derechos. Ante eso, la interventora evalúa la propia intervención desde la complejidad de los factores sociales que influyen en la categorización de la diferencia, y por tanto, surgen naturalmente emociones de tristeza y desesperanza.

Por otra parte, notamos que la institución escolar apareció como uno de los espacios emblemáticos de socialización con su grupo de pares y de juego, además, en casos de migración, ahí se establecen vínculos de integración social:

"Soledad. Pienso en niños y niñas sin muchos vínculos con otrxs con quienes socializar. Sin posibilidad de asistir a la escuela donde encontrarse con otros niños y niñas para jugar" (32 años, Chile, zona norte). 
En el discurso de la interventora aparece la escuela como un espacio de encuentro entre pares y lo perjudicados que están los niños en pandemia sin la vida escolar, debido al confinamiento. Así, la institución escolar se valora en su función de cuidado y protección social en un escenario de crisis, también se atribuye a ella su función de lograr una mejor calidad de vida, frente a situaciones de pobreza o desamparo. Además, se reconoce que la situación de la niñez migrante como vulnerabilidad genera una visión negativa, agravada hoy. También se evidencia la mirada generacional que logra ver al sujeto niñez como un grupo social que ha recibido poca atención de parte de las instituciones, lo que se expresa en el acceso a la educación a distancia en condiciones de precariedad:

"La primera idea que se me viene a la mente es negativa. Al leer infancia y migración de inmediato me hace pensar en crisis, vulneración, discriminación y violencia (de diversa índole). Si le sumamos el contexto de pandemia, la vulneración aumenta, puesto que la infancia -hasta el momento- no ha sido un grupo prioritario, ha sido marginada desde la salud, educación, prevención, recreación, entre otros. El grupo infantil migrante requiere de espacios seguros y propicios para la socialización, integración y desarrollo, espacios que actualmente dependen del acceso a tecnología y plataformas virtuales que muchas veces no están al alcance de la familia migrante" (23 años, Chile, zona norte).

"Pienso en la exclusión y desprotección. La situación de migración y la informalidad asociada a ésta (en términos laborales, habitacionales, etc.) sumada al cierre de jardines y escuelas, como espacios de cuidado y desarrollo, y a la falta de redes en el lugar de residencia, puede generar situaciones de riesgo, además del mayor empobrecimiento transversal a los sectores populares durante esta pandemia. Si el abandono del Estado es transversal a la pandemia, es aún mayor en el caso de las infancias migradas" (30 años, Chile, zona centro).

Como se observa en el discurso de estas interventoras, el rol de la escuela es conceptualizado como un espacio de colaboración en la crianza. Sin duda, el rol de la escuela, especialmente en el caso de la mediación e inclusión de la diferencia, es clave (Szulc, 2015). Las diferencias culturales en la escuela repercuten directamente en los aprendizajes de los estudiantes 'en abstracto' y además en términos cotidianos y concretos. Ciertamente, la clase en tanto categorización social comprende la distribución inequitativa del poder y del acceso a los bienes y derechos. La pobreza, por tanto, aparece como un factor preponderante en el acceso al ejercicio de derechos sociales para locales y migrantes. En este sentido, las condiciones de niñas y niños migrantes debido al COVID 19 plantea desafíos en la igualdad ante el quehacer educativo en ambientes virtuales. Si las condiciones que permiten el acceso a educación son limitadas para toda la niñez, observamos que las interventoras reconocen que las posibilidades de acceso se profundizan debido al eje edad-"raza"-nacionalidad. Es decir, la pandemia ha profundizado las brechas educacionales y de bienestar, puesto que las necesidades básicas para el aprendizaje y el cuidado no estarían cubiertas.

Otro conjunto de citas narrativas configura a la niñez migrante en la clásica representación social vinculada al futuro (Gaitán, 2006). Sabida es la permanente preocupación por el impacto que las diversas experiencias infantiles tendrán en el devenir adulto, pero, al mismo tiempo hay inquietud por la vida presente: 
"Siento temor por el futuro de estxs niñxs. Vulnerabilidad. Exposición. Abandono estatal" (23 años, Chile, zona norte).

Como se ha dicho, la representación de la infancia y el futuro ha estado imbricada respecto al desarrollo y los impactos que los eventos tendrán en el futuro, cuando abandonen la niñez y estén en la etapa adulta (Qvortrup, 2010):

"Marcando generaciones para un futuro, derechos vulnerados y poca empatía y comprensión hacia el grupo implicado" (30 años, Chile, zona norte).

Desprendemos de las palabras de las interventoras que esta representación de la infancia ligada al futuro aparece influida por el contexto. Es posible que la temporalidad a la que aluden sea, más bien, producto de su reflexión respecto del impacto del contexto sobre las condiciones de la infancia migrante ante la pandemia. Por tanto, nuevamente el contexto se convierte en un vehículo articulador de la diferencia, profundizando las brechas de clase. Adicionalmente, las interventoras reconocen el abandono estatal de la infancia migrante. En este sentido, desde una mirada fundada en el principio de la opresión, comprendemos que las interventoras adosan al estado la responsabilidad del abandono como un elemento hegemónico intencionado que incide en la profundización de la vulnerabilidad. La infancia es una fase del ciclo vital y un fenómeno sociológico, que está teñido de representaciones sociales. En el siguiente relato se enuncia el concepto de "crisis sanitaria" y se vincula con el aumento de las situaciones de riesgo para los grupos desfavorecidos, considerando que el grupo de la niñez también se ha contagiado del virus y que el desarrollo de vacunas específicas es reciente:

"El fenómeno de la migración influye en los procesos o etapa del ciclo vital, como es la infancia y cómo se asocia con la crisis sanitaria que estamos viviendo (ver múltiples factores tanto protectores como de riesgos). Infancia migrante y pandemia = inquietudes y desafíos. Niñez migrante en tiempo de COVID = vidas y futuros en riesgo"(32 años, Chile, zona norte).

Es interesante observar cómo reconfiguran las categorizaciones sociales que cooptan a la infancia migrante. Por un lado, la interventora indica una ecuación que deja de manifiesto la tensión entre el eje edad-nación-habilidad en el sentido de que la pandemia inhabilita las capacidades de participación social (Unicef, 2021; CEPAL, 2020; FIOCRUZ, 2020). Además, es posible observar una concepción de la infancia desde la protección de una vida futura dadas las condiciones actuales. La cuarentena a la que refiere Ariès (1963) o moratoria de Gaitán (2006) posee actualmente un correlato empírico, porque la niñez se encuentra efectivamente en confinamiento. No obstante, esta separación del mundo adulto que se manifiesta en las sociedades occidentales, y aumentada por la pandemia en el caso migratorio (Cabieses, 2020), deja de lado las capacidades para la actuación o performance que niñas y niños pueden evidenciar (Gaitán, 2006, García y Meriño, 2014). En este sentido, la interventora considera el riesgo en pandemia como una limitante futura respecto de las condiciones actuales, dejando de lado las respuestas y experiencias de niñas y niños ante el contexto del COVID 19. Sin embargo, creemos también que, aún adhiriendo a una concepción de la niñez como sujetas y sujetos 'aquí y ahora', la niñez se encuentra confinada en todo su actuar cotidiano. Indudablemente, la comprensión de la niñez migrante debe 
ser reelaborada a la luz del contexto. Como hemos evidenciado hasta aquí, una representación recurrente en los registros de las mujeres interventoras se relaciona con el concepto de vulnerabilidad, lo que por cierto está respaldado por las altas cifras de pobreza y exclusión y se expresa en la vulneración de derechos en tiempos de pandemia (UNICEF, 2021):

"Desigualdad frente a un marco normativo que sigue mostrando algunas dificultades en la garantía de derechos" (37 años, Chile, zona norte).

"Ahogo y vulnerabilidad" (27 años, España, zona centro).

"Abandono, precarización de la vida, deserción escolar" (30 años, Chile, zona centro).

"Efectos y consecuencias en el estilo y calidad de vida. Exigencias en cuanto a la adaptabilidad. Se me hace inevitable pensar en niños, niñas y adolescentes en situación de irregularidad quienes se enfrentan a vulnerabilidad en sus derechos y desprotección por parte del Estado" (25 años, Colombia, zona norte).

Una clara vulneración de derechos de la niñez migrante en Chile se observa en la alta tasa de irregularidad administrativa, en un escenario donde el tema migratorio se emplea electoralmente mediante las deportaciones televisadas (SJM, 2021). Otra representación de la infancia migrante en situación de vulnerabilidad se vincula con la mirada generacional transnacional, la cual es vista como un fenómeno que afecta al grupo total de la infancia migrante en la región latinoamericana, porque se cierran las fronteras y la movilidad parece una amenaza en plena pandemia:

"Las distintas formas de cómo la pandemia ha golpeado fuertemente a la comunidad migrante más vulnerable. Pienso en Ixs niñxs venezolanxs que tratan de cruzar la frontera chilena junto a sus padres y las autoridades les cierran 'las puertas'. En Ixs niñxs centroamericanxs y mexicanxs que cruzan la frontera solxs con el fin de encontrarse con sus familiares en EE.UU. y son deportados a México, un país en donde las políticas migratorias son insuficientes, sin hablar de lo peligroso que es vivir en México siendo niñx y mujer"(28 años, México, zona centro).

Podemos observar que la interventora reconoce el carácter multidimensional del riesgo y la vulnerabilidad. Es decir, los mecanismos tanto estructurales como cotidianos se establecen como un dispositivo de control sobre el sexo-género y la edad-generación. Bajo un análisis interseccional, comprendemos que la interventora reconoce el ejercicio de la violencia estructural sobre los cuerpos de las mujeres, donde se normaliza la vulneración de los derechos y se evade la incorporación del sexo-género como un elemento organizador de la política pública. Se ha comprobado que las niñas y las adolescentes migrantes pueden llegar a ser víctimas de diferentes tipos de violencia sexual desencadenando procesos de polivictimización, por razón del sexo-género, sin embargo, estas situaciones quedan altamente invisibilizadas (Pavez-Soto y Acuña, 2019). Otros relatos vinculaban la vulnerabilidad de la niñez migrante con un enfoque de sujeto de derechos, que debería tener espacios de participación, escucha y consideración de sus puntos de vista: 
"En lo duro, el estar viviendo en tan corta edad todo a la misma vez, dejar su país de origen, familia, escuela, amigos, tal vez, ni se le preguntó qué pensaba de irse de su país, a esto sumarle una pandemia por más de un año y żen qué circunstancias la estará viviendo? sin poder salir a jugar, tal vez, sin internet para ver sus clases, en hacinamiento, etc."(57 años, Venezuela, zona centro).

Desde el punto de vista de un análisis interseccional, el discurso crítico de la interventora evidencia la posición de invisibilización de la infancia migrante, por razones económicas y, falta de políticas públicas, una situación agravada por la pandemia:

"Vulneración de derechos, inestabilidad, desigualdad, esfuerzo y valentía. Me vienen estas palabras, porque creo que la pandemia ha venido a visibilizar todo eso. Las vulneraciones de derechos de los niños y niñas, producto de la desigualdad socioeconómica, hay niños que quedan en situaciones de exclusión, porque sus padres han migrado y se quedan al cuidado de otros. Porque el gobierno de sus países de origen no ha sido capaz de proveerles condiciones mínimas para una vida con dignidad ni tampoco el gobierno del país de destino para una reunificación familiar (porque al final la migración es un derecho inherente a cualquier ser humano). Inestabilidad, porque un niño que migra de un país a otro, sobre todo, en reiteradas ocasiones, corre el riesgo de no estar estable y vivir una infancia plena. " (26 años, Haití, zona centro).

En las palabras de la interventora podemos observar que la clase se configura como uno de los primeros elementos que organizan el discurso. En este sentido, uno de los primeros factores que inciden en la vulneración de derechos es la construcción de la figura del migrante como sujeto cooptado por la condición socioeconómica. Es decir, el ejercicio del derecho se comprende como un privilegio de clase al que el migrante no puede acceder, especialmente en los casos de migración irregular. Este impedimento es acarreado por los grupos familiares completos y repercute más profundamente en los procesos de desarrollo infantil. Por último, se halla una visión autocrítica de la infancia y sus representaciones en el nivel micro y macrosocial, a partir de un enfoque generacional:

"Pienso en las formas de representación de la niñez en las políticas y en los medios, y cómo el fenómeno migratorio incide en sus relaciones intergeneracionales, en el entrecruce de las dinámicas económicas y políticas, sobretodo en medio de una crisis sociosanitaria. Pienso en sus historias individuales y colectivas, desde los grandes relatos y procesos socio-educativos de salir y llegar a otro lugar" (30 años, Colombia, zona centro).

Otros relatos aluden a la complejidad del momento presente que enfrenta la vida infantil y la constatación del cambio de época en que se encuentra esta generación, evidenciando la ineludible transformación cultural y mundial. Sin duda, esta será una generación marcada por la pandemia, porque estamos ante un cambio cultural:

"Las combinaciones de estos tres elementos hacen que vengan a mi mente las siguientes palabras: Adaptación, Cambios, Procesos, Aprendizaje, Amor, Paciencia y Resiliencia" (23 años, Chile, zona norte).

"Pienso en la palabra desafío. Pues tanto la pandemia como la migración implican un cambio cultural respecto a las formas de percibir, ser y estar en el mundo. Siento que se está construyendo una nueva forma de estar en el mundo" (35 años, Colombia, zona norte). 
Esta transformación a la que aluden las mujeres interventoras implica, desde el principio relacional del análisis interseccional, comprender que las categorías sociales de la diferencia no son estáticas, es decir, se comprenden las unas a las otras de manera compleja de acuerdo con el contexto. Lo anterior implica, por ejemplo, revisar el concepto de niñez migrante -comprendida como una categoría sociológica- que yace latente en el discurso interventor y analizar cómo -en el contexto de pandemia- se ha visto afectada, en tanto grupo social vulnerable. Este ejercicio analítico permite ver la representación que se tiene de un fenómeno en particular y en qué medida va mutando. Dadas las nuevas condiciones del privilegio que hoy permiten la movilidad de ciertos sectores de la población situados preferentemente en contextos de gestión exitosa de la pandemia, la relación con otras movilidades como la que ocurre en pasos transfronterizos no habilitados también sitúa a la población migrante en una pérdida de estatus en favor de otros. Consecuentemente, se requiere de una reelaboración de los procesos migratorios. Los textos revelan una narrativa trágica que muestra el lado más sombrío de los efectos de la pandemia en el nivel social: niñeces abandonadas por los estados, en total desamparo y extrema fragilidad, que son atendidas por políticas poco amigables hacia este sujeto. La infancia migrante se configura como una alteridad carente, vulnerada en sus derechos, pero con la urgente necesidad de ser reconocida como protagonistas.

\section{La experiencia de infancia en las mujeres interventoras}

La segunda categoría de análisis estaba relacionada con la enunciación de la propia experiencia de infancia de las mujeres interventoras para resignificarla como un posible insumo en una eventual intervención con infancia migrante en periodo de pandemia. Las profesionales apuntaron la presencia de vínculos afectivos durante su infancia como factores protectores, los cuales son fundamentales para la niñez migrante durante la pandemia.

"Fue una infancia acompañada, en la medida de lo posible protegida, lo expongo así porque hay episodios no gratos de la infancia; de muchos amig@s, vínculo familiar, de mucho cariño, amor familiar" (32 años, Chile, zona norte).

"Protegida. La figura materna muy presente y la paterna en constante movimiento por trabajo" (32 años, Chile, zona norte).

En algunos discursos de las mujeres interventoras se puede apreciar la representación de diferentes formas de vivir su infancia, con episodios gratos y otros no tanto, con figuras paternas ausentes y figuras maternas protectoras. Esta diversidad de experiencias permite comprobar la pluralidad de las infancias -premisa sociológica del estudio- y abre un puente de conexión con las infancias "otras" (Parra, 2021), más allá de una infancia colonizada. Justamente, la infancia migrante emerge como una legítima "otra". En contraposición con esta pluralidad, una representación social que predominó en la narrativa de la propia infancia se vincula con la felicidad, la cual aparece en las frases como un mandato. La felicidad está directamente vinculada con la idea de la infancia como un paraíso perdido. Existe una premisa ampliamente compartida en el inconsciente colectivo y se refiere al grado de felicidad de la infancia será determinante para el presente y el futuro del sujeto: 
"Fue muy acontecida con recuerdos gratos y no tantos, pero prevalecen los momentos de mayor felicidad" (37 años, Chile, zona norte).

"Fue rodeada de mucho amor y cariño, con recuerdos felices y otros no tanto" (21 años, Chile, zona norte).

"Fue una infancia feliz con unos padres presentes, de compartir con mis hermanas, ir a la escuela, jugar, salir de vacaciones" (57 años, Venezuela, zona centro).

"Fue una infancia protegida, feliz, estable y religiosa" (27 años, España, zona centro).

La felicidad apuntada por las profesionales es comprendida según sus propias experiencias vividas en la niñez. Una joven mujer interventora de origen migrante señaló abiertamente que no tuvo una infancia feliz, debido a una separación conyugal que desencadenó en procesos de institucionalización y movilidad, que se recordaron con emociones intensas, como el arrebato de un tesoro. Esta experiencia en primera persona de una mujer migrante se puede leer como una práctica de resistencia epistémica e interseccional (Collins \& Bilge, 2020), porque podría nutrir la mirada y empatía hacia la niñez migrante de hoy, en circunstancia de pandemia:

"Mi infancia no ha sido de la manera que me gustaría recordarla, (siendo plenamente feliz). Porque no tuve la oportunidad de vivir mi infancia en un hogar estable, cálido, lleno de amor. Primero, porque mis padres se separaron cuando tenía dos años de edad, desde ese momento empiezo a experimentar procesos de migración. Luego, me arrebataron a mi padre a la edad de 9 años." (26 años, Haití, zona centro).

Una de las conclusiones es que la edad configura el estatus social de la persona migrante. Por tanto, el ejercicio del poder a través de condiciones estructurales que permiten y fomentan la categorización social impacta las vidas de los individuos. En este caso, el origen nacional distinto y la edad se confabulan para un ejercicio del poder disminuido en comparación a otras infancias y otras/os migrantes. Igualmente, la opresión que se produce desde el mundo adulto a la niñez crea un margen de acción minoritario para la toma de decisiones, lo que afecta el bienestar emocional, provocando sentimientos de inestabilidad. Sin embargo, los vínculos familiares suelen favorecer el proceso migratorio.

En otros relatos, se aprecia una visión autocrítica de la experiencia de infancia personal, por ejemplo, a pesar de haber vivido la infancia en condiciones de escasez material, emergen figuras sociales resignificadas en el debate público actual, como las redes de apoyo mutuo, el territorio o el espacio del barrio:

"Mi infancia fue acompañada por mis tres hermanas y ambos padres. Se dio (sic) en un contexto de escasos recursos, en donde la unión del barrio fue crucial para mi desarrollo y vinculación con personas de mi edad. Gocé de una infancia feliz y tranquila, puesto que mis padres nos brindaron todo lo necesario para nuestro crecimiento y desarrollo, más allá del alimento y el techo, nos brindaron de un ambiente familiar, relaciones de respeto y un entorno seguro donde pudiéramos desenvolvernos sin prejuicio" (23 años, Chile, zona norte). 
Ciertamente, la criatura humana precisa de cuidado; tanto el bebé recién nacido como las niñas y los niños más pequeños o más vulnerables tienen derecho al regaloneo -chilenismo que alude a la práctica de demostrar cuidado, cariño y/o preocupación. Sin embargo, ese pequeño ser también es un sujeto de derechos que requiere moverse en libertad de acción y pensamiento, es un ser vivo en permanente interacción y cambio, un actor social protagonista de su existencia y que experimenta las contradicciones. Así lo podemos ver en la siguiente cita de una niña quien se autodefine con el adjetivo chileno de "regalona", ella se reconoce o toma consciencia como primogénita mujer, en una genealogía femenina y familiar, la cual también podría ser leída en clave de resistencia interseccional a la hora de intervenir, ahora, con niñas migrantes en un contexto de pandemia:

"Mi infancia fue viajera, soñadora y regalona, siempre acompañando a mis padres a todos los lugares que iban, regalona por ser la primera mujer, después de diez años de diferencia con mi hermano que me antecede, hasta los siete años, cuando nace mi hermana menor" (30 años, Chile, zona norte).

La familia se destaca en la comprensión de esta interventora como algo positivo de su infancia. Podemos ver en el discurso de la interventora que dentro del núcleo familiar su posición de poder y privilegios operaron en favor de su sexo-género. Como hemos indicado anteriormente, las categorías sociales son dinámicas, en consecuencia, no pueden establecerse como productos que resultan en mayor o menor medida de la hegemonía, en este caso, sexo-genérica. Respecto de esto último, creemos necesario explicitar que la feminización de los cuidados ha sido interpretada como una carga (Carrasco, 1998) o como un espacio de empoderamiento femenino (Gilligan, 2003). Creemos que el cuidado es un ámbito contradictorio, tal como expusieron nuestras participantes, y en constante negociación entre las relaciones que se producen en el nivel inter e intra-categorización. En ese sentido, el análisis debe prestar oídos a lo que Misra et al (2021) han denominado contexto. En esta red de cuidados la figura de la abuela emergió como otra actora social visibilizada en su rol cuidador y de "regaloneo", en el cruce de relaciones intergeneracionales que se intersectan con el sexo-género:

"Fui criada por mi abuela (porque mis padres trabajaban), sin embargo, siempre estuve rodeada de amor, atención y comprensión. A pesar de que mis padres trabajaran, mi mamá (sic) siempre que llegaba del trabajo me 'regaloneaba' e intentaba ayudarme con algunas tareas (sic)" (23 años, Chile, zona norte).

Otro aspecto destacado por las participantes del estudio es que algunas de ellas reconocían haber tenido buenas condiciones materiales durante la infancia, lo cual fue enunciado en clave de privilegio. Tal vez, esta especie de autoimpugnación responde a una crítica surgida en el debate post-estallido social y se refiere a visibilizar y renunciar a los llamados privilegios que emanan de las jerarquías de clase, nacionalidad o sexo-género, entre otras categorías. Acto seguido, se evidenció un nudo temático contradictorio por haber vivido situaciones de bienestar material, ya que se aclara que igualmente vivían dificultades afectivas o emocionales. Esta dualidad permitió superar la visión antagonista de la infancia y 
esbozó una experiencia densa. Cuando se hablaba en primera persona del fenómeno se desplegaba empatía y conexión, aprendizaje desde algún tipo de adversidad y práctica de resistencia interseccional:

"Mi infancia estuvo acompañada de mi hermana y hermano (entre los tres nos llevamos pocos años de diferencia), lo que nos permitió siempre estar juntos, como hasta ahora, con los mismos juegos y peleas. Siempre me sentí cuidada y protegida económicamente, una vida tranquila, pero emocionalmente, creo que abordamos (abordo) muchas situaciones complejas de mi madre y padre" (30 años, Colombia, zona centro).

"Relativamente privilegiada en términos materiales" (30 años, chilena, zona centro). "Privilegiada en relación a lo material y económico, quizás más solitaria en cuanto al desarrollo emocional" (31 años, Chile, zona centro).

"Fue una infancia protegida en lo material/económico, quizás un poco menos en lo emocional, en relación a las herramientas con las que contaban mis padres" (30 años, Chile, zona centro).

Las interventoras resisten, en parte, la categorización social que les otorga mayor poder o privilegios de clase. No obstante, la empequeñecida protección de la niñez, en concreto respecto de las garantías de bienestar emocional infantil provistas desde el mundo adulto, proviene de la categorización social. Es decir, la infancia es desprovista transversalmente de distintos mecanismos protectores respecto de su cuidado producto del poder que ejerce el mundo adulto sobre el mundo infantil. La paradoja es de difícil abstracción sin caer en el reduccionismo. Dicho de otro modo, la tendencia interpretativa nos compele a reducir el uso de la opresión adulta como garantía de bienestar de las niñas y niños; sin embargo, esta construcción deja de lado la fluidez del poder por otras categorías, como la sexo-genérica, que podría impactar de distintos modos en la experiencia.

En la narración de la propia infancia se hizo un reconocimiento de ciertos mandatos de edad y sexo-género, un deber-ser que caía como una exigencia más, especialmente cuando se enfrentaban situaciones difíciles, como la separación, la monomarentalidad o el cuidado extenso:

"Recuerdo sentir desde muy pequeña la responsabilidad de "ser una buena niña". Mis padres se separaron cuando era muy pequeña, y mi madre como mamá soltera se encargó de nosotras (mi hermana y yo) y de mi sobrino, quien siempre ha sido el regalón de la casa. En ese sentido, siento que fue (desde que puedo recordar, unos 6 años) muy exigente, antes de eso no tengo muchos recuerdos, pero comentan que fue muy buena y alegre" (25 años, Colombia, zona norte).

Como se puede apreciar en la cita recién expuesta, la figura femenina es representada como la responsable del cuidado infantil. La comprensión de la categorización de sexo-género como un elemento fluido -así como lo son las otras categorizaciones- permite comprender que el sujeto padece de manera compleja la opresión, porque en este caso, igualmente lleva a cabo una resistencia como respuesta a la distribución inequitativa del poder, no es una categorización que se acepta pasivamente. Las categorías sociales tienen un carácter maleable, el estatus y el privilegio en tanto respuesta a las condiciones impuestas 
por las hegemonías socioculturales son negociados, contextuados y resistidos, ajustando y reconfigurando las condiciones de poder que ostenta cada categoría. En esta constante reconfiguración del poder, las niñas, los niños y las mujeres van transformando su rol en el cuidado, porque también constituye un ámbito de poder y un campo de conflicto y negociación sexo-genérica e intergeneracional. De hecho, durante la pandemia ha quedado al descubierto este conflicto, de modo particular en las familias más vulnerables, donde además se cruzan condiciones estructurales o de clase. Justamente, de acuerdo al relato de las mujeres interventoras es en esos cruces, avenidas y semáforos donde se ubica la infancia migrante, en tanto infancia "otra" (Parra, 2021). ${ }^{3}$

\section{Conclusiones}

La vulneración de derechos que sufre la infancia migrante durante la crisis sanitaria puede leerse como una manifestación macrosocial de la desventaja o subordinación en que queda situada, en tanto este grupo social. La pandemia ha impactado negativamente en su calidad de vida presente, pero también podría tener impactos en su vida futura. Las mujeres interventoras de esta llamada "primera línea social" mostraron una alta sensibilidad frente a la vulnerabilidad y a las dificultades generadas por la crisis y que afligen a la población migrante hoy. Los relatos y las opiniones tejieron nudos temáticos en torno a visiones y emociones contradictorias, reflejos de este momento de incertidumbre y reconfiguración, como, por ejemplo, soledad y vínculos, desigualdad e inclusión, riesgo y protección, trauma y ahogo, cambio de época y cambio generacional.

Un primer hallazgo se vincula con la enunciación, el registro y el tono semántico utilizado para hablar de la propia infancia. Cuando se habla de la infancia migrante, en tanto otredad, se percibe una tendencia hacia conceptos tales como vulnerabilidad, exclusión, futuro y riesgo; mientras que cuando se habla en primera persona se hace un nexo hacia las representaciones sociales relativas a la idealización, felicidad, divino tesoro, regaloneo y una pugna entre lo material y afectivo. Sin ánimo de querer escudriñar en los fantasmas o traumas que podrían alojar en cada experiencia íntima, la idea del estudio consistía en tomar la propia experiencia de infancia como un referente a la hora de la intervención en momentos de crisis, una caja de herramientas experienciales, no teóricas, echando mano de un método biográfico de intervención, tomando distancia crítica del aura de objetividad y poder de la intervención. Ellas también fueron niñas una vez y esa enunciación igualmente se hace presente en la praxis (tal vez, de modo inconsciente). Así, la primera imagen

3 Un nudo crítico que atravesó oblicuamente los discursos de las interventoras fue la resistencia epistémica sobre el eje sexo-género en el lenguaje, a través del ejercicio de actos de habla cuya fuerza resiste la categorización social (Butler, 1997). La utilización de la X y la $\mathrm{E}$ en reemplazo de los morfemas de género disputaba las normas hegemónicas del lenguaje, estableciendo una semiótica distinta y abierta. En este sentido, las interventoras fueron capaces de reconfigurar una relación indisoluble entre performatividad y lenguaje a través de la elaboración de marcadores discursivos que refrendan una concepción desafiante del eje sexo-género. Además, la autodefinición como mujeres identificadas con el sexo-género femenino también evidenció una toma de conciencia de su naturaleza sexuada. El instrumento de recogida de datos que permitió la escritura nos reveló una apropiación del lenguaje, en tanto némesis de las normas lingüísticas de género gramatical, utilizado como elemento detonador de una nueva semiótica o una toma de posiciones. 
que se dibujó es de idealización, la propia infancia es ese paraíso perdido del cual fuimos expulsadas y al cual jamás volveremos. La propia infancia es un relato imposible, cargado de afectos y subjetividad, es la infancia real, la de las cicatrices en la rodilla y es la infancia ideal, la que nos sostiene en cuanto a nuestra biografía y, tal vez, un motor para el propio trabajo desplegado.

En la propia experiencia de infancia aparece latente la idea de los derechos, en especial, la protección. Cuando se narra en primera persona, ciertas situaciones complejas asumen una perspectiva de mayor comprensión y se evidencian elementos claves de la vida infantil, como los lazos afectivos, la presencia de la familia extensa, las amistades y el grupo de pares, la naturaleza, los viajes y el regaloneo. El punto de vista de los hechos emerge como algo más realista, menos negativo, si bien se reconocen vivencias de vulnerabilidad material y afectiva, más allá del malestar, se interpreta como una fuente de aprendizaje.

Este estudio constituye una primera aproximación hacia comprender de qué modo las representaciones sociales de la infancia podrían influir en la configuración de la niñez migrante. Tras el análisis de los datos recopilados podemos concluir que las visiones de infancia de las mujeres interventoras son diferenciadas en cuanto a hablar de la propia experiencia o cuando se enuncia un discurso sobre "otra" infancia. La niñez migrante, en tanto grupo social, representa una especie de alteridad. En las páginas precedentes se pudo apreciar que las representaciones sociales de infancia fluctúan entre conceptos disímiles como la felicidad, el juego y el regaloneo, pero también aparece el abandono, el riesgo y la tristeza. Nuestra hipótesis de investigación indicaba que las representaciones sociales de infancia influyen en los imaginarios de la intervención y, por lo tanto, tendrían algún efecto en la vida concreta de la niñez migrante, en el caso de una eventual intervención de parte de la ONG durante la época de pandemia. Analizar las palabras y las imágenes que usamos para referirnos a los fenómenos sociales permite comprender los paradigmas que sustentan la praxis. El lenguaje construye la realidad, la moldea y la transforma.

El principal hallazgo de nuestro estudio dice relación con la reconfiguración de las representaciones sociales de la categoría infancia, ya sea en el sujeto migrante y en la propia sujeta interventora. Desde un prisma interseccional, el contexto como principio de análisis resulta prominente durante la pandemia y postpandemia, debido a las relaciones de categorización social. Por ejemplo, las condiciones de vida precarizada en tiempos de COVID 19 afectan el estatus de la población infantil migrante y aumenta la demanda por intervenciones sociales situadas y pertinentes. Esta investigación a través de un marco teórico, metodológico y epistemológico interseccional ha permitido develar las tensiones propias del ejercicio del poder hegemónico. Sin duda, este lente interseccional nos permitió comprender de mejor manera la movilización del poder en el discurso de las interventoras y cómo ellas, a su vez, actúan, proyectan y resisten la categorización social. 


\section{Agradecimientos}

En este artículo se presentan resultados del proyecto de investigación interno DIRI $N^{\circ}$ 0002/2021 "Intervención con infancia migrante en pandemia: representación y referente" financiado por la Dirección de Investigación de la Universidad Bernardo O'Higgins. Las autoras expresan su agradecimiento a las mujeres interventoras que participaron en el estudio.

\section{Bibliografía}

Alliance for Child Protection in Humanitarian Action. (2020). Technical Note Summary: Protection of Children during the COVID-19 Pandemic (English v.1). https://alliancecpha.org/en/COVID19summary

Ariès, P. (1962). Centuries of Childhood. Londres, Inglaterra: Cape.

Bourdieu, P. (2008). El oficio de sociólogo. Madrid, España: Cátedra.

Butler, J. (1997). Lenguaje, poder e identidad. Madrid, España: Síntesis.

Cabieses, B. (2020). Encuesta sobre Covid-19 a poblaciones migrantes internacionales en Chile. Informe de resultados completo. Recuperado de: https:// repositorio.udd.cl/bitstream/handle/1 1 447/3267/REPORTE\%20FINAL\%20ENCUESTA\%20MIGRANTES\%20Y\%20COVID19.pdf

Carrasco, C. (1998). Género y valoración social: la discusión sobre la cuantificación del trabajo de las mujeres. Mientras Tanto, (71), 61-79.

Choo, H. Y. \& Ferree, M. M. (2010). Practicing Intersectionality in Sociological Research: A Critical Analysis of Inclusions, Interactions, and Institutions in the Study. Sociological Theory, 28(2),129-149. doi:10. $1111 /$ j.1467-9558.2010.01370.x

Centro de Investigación Periodística (CIPER). (2021). Criar y crecer en tiempos de COVID: cómo la pandemia ha deteriorado el bienestar de madres, padres y niñas/os. Recuperado de: https://www.ciperchile.cl/2021/04/05/criar-y-crecer-en-tiempos-de-covid-como-la-pandemia-ha-deteriorado-el-bienestarde-madres-padres-y-ninas-os/

Collins, P. H. (2019). Intersectionality as Critical Social Theory. Durham, NC: Duke University Press.

Collins, P. H. \& Bilge, S. (2020). Intersectionality. Canada, Montreal: John Wiley and sons.

Comisión Económica para América Latina y el Caribe (CEPAL) (2020). Los efectos del COVID 19: una oportunidad para reafirmar la centralidad de los derechos humanos de las personas migrantes en el desarrollo sostenible. Informes Covid 19. Recuperado de : https://www.cepal.org/sites/default/files/publication/files/46353/S2000618_es.pdf

Comisión Económica para América Latina y el Caribe (CEPAL) \& Fondo de las Naciones Unidas para la Infancia (UNICEF). (2020). Los efectos del Covid-19, una oportunidad para reafirmar la centralidad de los derechos humanos de las personas migrantes en el desarrollo sostenible. Informe del Primer Diálogo virtual. Recuperado de :https://www.cepal.org/sites/default/files/events/ files/informe_dialogo_virtual_migracion_internacional_0.pdf

Departamento de Estadísticas e Información e Información de Salud (DEIS). (2021). Descripción Epidemiológica de Niños, Niñas y Adolescentes con COVID-19. Chile. 2020-202 1. Informe Epidemiológico. Recuperado de: https:// WWW.minsal.cl/wp-content/uploads/2021/04/Informe-epidemiológico-COVID-19-en-niños-niñas-y-adolescentes_SE_9-11_2020-2021.pdf

FIOCRUZ. (2020). Crianças na pandemia COVID- 19. Recuperado de: https://www. fiocruzbrasilia.fiocruz.br/wp-content/uploads/2020/05/crianc\%CC\%A7as_ pandemia.pdf

Fondo de las Naciones Unidas para la Infancia (UNICEF). (2021). Midiendo el impacto de la COVID-19 en los niños y niñas menores de seis años en América Latina. Recuperado de: https://www.unicef.org/lac/media/20556/ file/Midiendo\%20el\%20impacto\%20de\%20la\%20COVID-19\%20en\%20los\%20 ninos\%20y\%20ninas\%20menores\%20de\%20seis\%20anos\%20en\%20Ameri- 
ca\%20Latina\%20y\%20el\%20Caribe.pdf

Gaitán, L. (2006). Sociología de la Infancia. España, Madrid: Síntesis.

Galaz, C. J. y Rubilar Donoso, M. G. (2018). Experiencias profesionales en intervención psicosocial: el ejercicio narrativo como metodología de reflexividad y vigilancia epistemológica. Revista Latinoamericana de Metodología de las Ciencias Sociales, 9(1), e050. https://doi.org/10.24215/18537863e050

Galaz, C. (2016). Producciones narrativas: la agencia y reflexividad en las prácticas de interventoras sociales. V Encuentro Latinoamericano de Metodología de las Ciencias Sociales, 16 al 18 de noviembre de 2016, Mendoza, Argentina. Métodos, metodologías y nuevas epistemologías en las ciencias sociales: desafíos para el conocimiento profundo de Nuestra América. En Memoria Académica. Disponible en: http://www.memoria.fahce.unlp.edu.ar/trab_eventos/ev.8441/ev.8441.pdf

García, A. \& Mariño, K. (2014). Agencia y construcción de identidad en niños con enfermedad respiratoria crónica. Tesis de máster. Universidad pedagógica Nacional, Bogotá, Colombia.

Gilligan, C. (2003). La ética del cuidado. España, Barcelona: cuadernos de la Fundació Victor Grifol i Luca. Disponible en: http://www.secpal.com/\%5CDocumentos\%5CBlog\%5Ccuaderno30.pdf

Krippendorff, K. (2018). Content analysis: An introduction to its methodology. Londres, Inglaterra: Sage publications.

Mayall, B. (2002). Towards a sociology for childhood. Thinking from children's lives. EE UU, Philadelphia: Open UniversityPress.

Moscovici, S. (1988). Notes towards a description of social representations. European Journal of Social Psychology, (18), 211-250.

Misra, J.; Vaughanm Curington, C. \& Mary Green, V. (2021) Methods of intersectional research, Sociological Spectrum, (41),1, 9-28, DOI: 10.1080/02732173.2020.1791772

Muñoz García, P. (2020). (Des)protección de los derechos de la infancia en el contexto de la pandemia. Anales de la Universidad de Chile, (17), pp. 289301. doi:10.5354/0717-8883.2020.58929

Núñez Torrealba, C.. (2021). Linguistic ideologies within social representations in the identity of an EFL learner: A multi-case mixed study of Chilean adult learners of English. Tesis de Magíster en Linguística Aplicada al Inglés como Lengua Extranjera, Pontificia Universidad Católica de Chile.

Parra, M. (2021). Infancias y adolescencias "otras": Acciones comunitarias desde una sociología de las emergencias y una politicidad en clave femenina. Trenzar. Revista De Educación Popular, Pedagogía Crítica E Investigación Militante (ISSN 2452-4301), 3(6), 40-60. Recuperado de: https://revista.trenzar.cl/ index.php/trenzar/article/view/130

Pavez-Soto, I. y Acuña, V. (2019). Niñas migrantes en Chile: Vivencias en torno al acoso callejero y violencia sexual, Revista Señales, Servicio Nacional de Menores. (21), XII (2), 36-47. Recuperado de: https://www.sename.cl/web/ wp-content/uploads/2020/02/Revista-Senales-21_13-02-2020.pdf

Pujadas, J. J. (2000). El método biográfico y los génerós de la memoria. Revista De Antropología Social, (9), 127. Recuperado de: https://revistas.ucm.es/index. php/RASO/article/view/RASO0000110127A

Qvortrup, J. (2010). A infância enquanto categoria estrutural. Educação e Pesquisa, 36 (2), 631-644. https://www.redalyc.org/articulo.oa? id=29815818014

Scott, J. (2003[1986]). "El género: una categoria útil para el análisis histórico". En: Lamas, M. (Comp.). El género. La construcción cultural de la diferencia sexual. México, DF: UNAM-PUEG, p.265-302.

Servicio Jesuita a Migrantes, SJM (2021). Migración en Chile. Anuario 2020. Medidas Migratorias, vulnerabilidad y oportunidades en un año de pandemia $\left(\mathrm{N}^{\circ} 2\right)$. Chile, Santiago. Recuperado de https://www.migracionenchile. cl/publicaciones 
Szulc, A. (2015). Concepciones de niñez e identidad en las experiencias escolares de niños mapuche del Neuquén. Anthropologica, 33(35), pp. 235-253.

Toro Castillo, B. (2020). Intervención Social y SENAME: Análisis crítico de discursos de mujeres interventoras. Revista Trabajo Social (93), en línea, https://doi. org/10.7764/rts.93.59-74/ ISSN 0716-9736

Valles, M. (2003). Técnicas cualitativas de investigación social. España, Madrid. Síntesis.

Williams, R. (1997[1977]). Marxismo y literatura. España, Barcelona: Península.

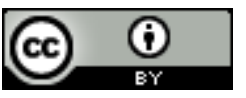

Este es un artículo de acceso abierto bajo licencia Creative Commons Reconocimiento 4.0 Internacional 